\title{
Vegetation structure determines cyanobacterial communities during soil development across global biomes
}

\author{
Concha Cano-Díaz ${ }^{1, *}$ \\ Fernando T. Maestre ${ }^{2,3}$ \\ Juntao Wang ${ }^{4,5}$ \\ Jing $\mathrm{Li}^{4,5,7}$ \\ Brajesh Singh ${ }^{4,5}$ \\ Victoria Ochoa ${ }^{2,3}$ \\ Beatriz Gozalo ${ }^{2,3}$ \\ Manuel Delgado-Baquerizo ${ }^{6}$
}

${ }^{1}$ Departamento de Biología, Geología, Física y Química Inorgánica, Escuela Superior de Ciencias Experimentales y Tecnología. Universidad Rey Juan Carlos, Móstoles, 28933, Spain

IInstituto Multidisciplinar para el Estudio del Medio "Ramon Margalef", Universidad de Alicante, Edificio Nuevos Institutos, Carretera de San Vicente del Raspeig s/n, 03690 San Vicente del Raspeig, Spain

${ }^{3}$ Departamento de Ecología, Universidad de Alicante, Carretera de San Vicente del Raspeig s/n, 03690 San Vicente del Raspeig, Alicante, Spain

${ }^{4}$ Global Centre for Land Based Innovation. University of Western Sydney, Penrith, 2751, New South Wales, Australia

${ }^{5}$ Hawkesbury Institute for the Environment, University of Western Sydney, Penrith, NSW, 2751, Australia

${ }^{6}$ Departamento de Sistemas Físicos, Químicos y Naturales, Universidad Pablo de Olavide, 41013 Sevilla, Spain

${ }^{7}$ Institute of Wetland Research, Chinese Academy of Forestry, Beijing Key Laboratory of Wetland Ecological Function and Restoration, Beijing, 100091, China

*Author for correspondence, e-mail: conchacanodiaz@gmail.com 


\section{Summary}

- Soil cyanobacteria play essential ecological roles and are known to experience large changes in their diversity and abundance throughout early succession. However, much less is known about how and why soil cyanobacterial communities change as soil develops from centuries to millennia, and the effects of aboveground vegetation on these communities.

- We combined an extensive field survey including 16 global soil chronosequences across contrasting ecosystems (from deserts to tropical forests) with molecular analyses to investigate how the diversity and abundance of soil cyanobacteria under vegetation change during soil development from hundreds to thousands of years.

- We show that, in most chronosequences, the abundance, species richness and community composition of soil cyanobacteria were relatively stable as soil develops (from centuries to millennia). Regardless of soil age, forest chronosequences were consistently dominated by non-photosynthetic cyanobacteria (Vampirovibrionia), while grasslands and shrublands were dominated by photosynthetic cyanobacteria. Chronosequences undergoing drastic vegetation shifts during soil development (e.g. transitions from grasslands to forests) experienced significant changes in the composition of soil cyanobacteria communities.

- Our results advance our understanding of the ecology of cyanobacterial classes, specially the understudied non-photosynthetic ones and highlight the key role of vegetation as a major driver of their temporal dynamics as soil develops.

Keywords: 16S amplicon sequencing, abundance, Cyanobacteria, Illumina sequencing, non-photosynthetic cyanobacteria, soil chronosequence, richness. 


\section{Introduction}

Cyanobacteria are a diverse and functionally important group of microorganisms on Earth. This phylum includes microbes with a wide range of metabolic capabilities from the photosynthetic cyanobacteria (class Cyanobacteriia), which live in most types of illuminated environments (Whitton \& Potts, 2012), to non-photosynthetic clades such as Vampirovibrionia and Sericytochromatia (Shih et al., 2017; Soo et al., 2017). A wide variety of life strategies are included in the phylum, from autotrophic to parasitic ones including multiple symbioses with plants and animals (Lindo et al., 2013; Soo et al., 2015, Benavent-Gonzalez 2019). In soil environments, cyanobacteria are globally distributed (Moreira et al., 2013; Cano-Díaz et al., 2020) and have an estimated biomass that can reach $54 \times 10^{12} \mathrm{gC}$ (Garcia-Pichel et al., 2003). They are also important components of biological soil crusts (Büdel et al., 2016), which cover up to $12 \%$ of Earth's terrestrial surface (Rodriguez-Caballero et al., 2018).

Soil cyanobacterial communities are known to undergo profound changes in their abundance, diversity and composition during the first days to decades of primary and secondary successions(Kastovská et al., 2005; Nemergut et al., 2007; Schmidt et al., 2008a; Dojani et al., 2011; Arróniz-Crespo et al., 2014). Filamentous nonheterocystous (without heterocytes) cyanobacteria as Microcoleus vaginatus appear first and contribute to soil stabilization through their rope-like bundles and exopolysaccharide sheath that binds soil particles together (Mazor et al., 1996; GarciaPichel \& Wojciechowski, 2009). Then, heterocystous nitrogen-fixers become more abundant and contribute to enhance soil microhabitat conditions, facilitating the colonization and further development of vegetation and other organisms (Danin et al., 1998; Garcia-Pichel \& Wojciechowski, 2009; Singh et al., 2016). When this happens, the abundance of cyanobacteria decreases and they no longer constitute the dominant fraction of the soil (Schmidt et al., 2008b; Maier et al., 2018). Despite the fundamental ecological roles they play, much less is known about how cyanobacterial communities change as soil develops from centuries to millennia, and their relationship with vegetation structure changes with time. Furthermore, non-photosynthetic classes are particularly understudied (Soo et al., 2014, 2017) and because of their inferred metabolic capabilities, their abundance could increase with soil development due to 
the raise of organic matter or by the opening of new ecological niches (Laliberté, 2014; Laliberté et al., 2017), but empirical evidence of this is largely lacking.

Direct observation and experimental manipulations in natural ecosystems over long time periods are not easy to obtain, therefore the use of long-term chronosequences is a suitable indirect alternative to explore them (Walker et al., 2010; Blois et al., 2013). Soil chronosequences imply a set of sites from the same parental material forming a spatial gradient that represents different stages of soil development. These space-for-time substitutions, which have successfully been used to characterize temporal changes in multiple ecological processes (Bardgett et al., 2005; Blois et al., 2013), have demonstrated that vegetation structure and soil nutrient contents shift during ecosystem development. For example, plant cover, soil carbon and nitrogen, which are mainly associated to biological activity, are known to increase as soil develops (Vitousek, 2004; Wardle et al., 2004; Laliberté, 2014), while soil phosphorous is known to decrease over millennia due to weathering and leaching (Vitousek, 2004). The main groups of photosynthetic and non-photosynthetic cyanobacterial taxa are known to be strongly associated with vegetation structure, soil pH and nutrient content at the global scale (Dini-Andreote et al., 2014; Cano-Díaz et al., 2020), and therefore, might also undergo through predictable changes in diversity, abundance and composition as soil develops from hundreds to thousands of years. However, this has not been tested in the field yet.

Here, we investigate how the abundance, diversity and composition of soil cyanobacterial communities under vegetation change as soil develops from hundreds to thousands of years across contrasting ecosystem types. We used the most comprehensive soil chronosequence standardized survey conducted to date (DelgadoBaquerizo et al., 2019), which includes 16 global chronosequences from polar ecosystems and deserts to temperate and tropical forests and encompass a wide range of climatic conditions, vegetation types and soil ages (from 10 to $5^{*} 10^{6}$ years). This database has been previously used to identify the overall changes in the richness (number of species) of soil bacteria, fungi, protists and invertebrates (DelgadoBaquerizo et al., 2019). However, the changes in the diversity and abundance of soil cyanobacteria remains unexplored. Using this unique chronosequence survey, we tested the following hypotheses: 
H1. Soil age indirectly regulates soil cyanobacterial communities. We hypothesized that relatively young and sparsely vegetated soils (from years to decades) could be potentially dominated by Cyanobacteriia and specifically by nitrogen-fixing cyanobacteria. We expect this because, unlike for nutrients associated with bedrock (e.g., phosphorus), young soils are limited by organic carbon and nitrogen (Hooper et al., 2000; Wardle et al., 2004), which are fixed by biological communities (Belnap, 2002; Hayat et al., 2010). This way, diazotroph-dominated cyanobacterial communities might play critical roles in the functioning of relatively young ecosystems (Brankatschk et al., 2011). As soils develop, with the accumulation of nutrients and the availability of new potential niches linked to vegetation succession (Van der Putten et al., 2013), we expect to find an increase in the abundance of non-fixing $\mathrm{N}$ cyanobacteria and the switch to more heterotrophic communities including non-photosynthetic cyanobacteria (Laliberté et al., 2017).

\section{H2. Biome type determines the structure of soil cyanobacterial communities} regardless of soil age. Climate and ecosystem-level soil properties and vegetation might uniquely influence the abundance, composition and diversity of soil cyanobacteria regardless of soil age. For example, we would expect low light conditions and acid soils from tropical and temperate forests to harbor different cyanobacterial communities than those from deserts or cold ecosystems. There, adaptations to dessication and high sun exposure due to the sparse or minimum vegetation are expected. Similarly, climatic conditions, rather than soil age, are expected to regulate the proportion of cyanobacterial with different functional capabilities e.g, non-photosynthetic vs, photosynthetic cyanobacteria (Cano-Díaz et al., 2020). 


\section{Materials and Methods}

\section{Chronosequence survey and soil analyses}

We obtained cyanobacterial 16S rRNA gene sequences from a global survey of 16 soil chronosequences from six continents conducted between 2016 and 2017 (DelgadoBaquerizo et al., 2019) (Fig.1). These chronosequences include a wide range of soil ages (from centuries to millennia), vegetation types (grasslands, shrublands, forests and croplands), origins (volcanic, sedimentary, dunes and glacier) and climatic types (tropical, temperate, continental, arid and polar).

All field surveys were conducted following a standardized sampling protocol, with a plot size selected to accommodate the different plant sizes and ecosystem types covered in our study. Each chronosequence was divided in 4-10 stages related to soil age (soil age was determined with radiometric dating measurements, references and measurements in Supplementary Tables ST1 and ST2; further details in DelgadoBaquerizo et al., 2019). Each stage was sampled using a $50 \times 50 \mathrm{~m}$ plot with three parallel transects of $50 \mathrm{~m}$ spaced apart $25 \mathrm{~m}$. Total plant cover and the number of perennial plant species (plant richness) was measured in each transect with the linepoint intercept method (Tongway \& Hindley, 2004). We obtained the standardized average of mean temperature (MAT) and precipitation (MAP) per plot using climatic data from www.worldclim.org. Aridity Index (precipitation/potential evapotranspiration) was obtained from the Global Potential Evapotranspiration database (Zomer et al., 2008), which uses interpolations from WorldClim. At each plot, five composite soil samples $(0-10 \mathrm{~cm}$ depth) were collected under the dominant vegetation and sieved $(2 \mathrm{~mm})$ back in the laboratory. The collection depth could be diluting the abundance of light dependant photosynthetic cyanobacteria in favor to the non-photosynthetic classes. However since soils are always collected at the same depth, relative increases and decreases in cyanobacterial types with time are directly comparable. A fraction of the sieved soil was immediately frozen at $-20 \circ \mathrm{C}$ for molecular analyses; the other fraction was air-dried for biochemical analyses. We retrieved $10 \mathrm{~g}$ from each frozen composite soil sample and ground it with a mortar and liquid $\mathrm{N}$ to obtain a homogenized representative sample. Soil DNA was extracted 
afterwards with the PowerSoil DNA Isolation Kit (MoBio Laboratories, Carlsbad, CA, USA), following manufacturer's instructions.

All soil analyses were done in all samples in Rey Juan Carlos University (Spain) to facilitate the comparison of results. Soil $\mathrm{pH}$ was measured in a 1:2:5 suspensions of dry mass to deionized water volume with a $\mathrm{pH}$ meter, and ranged from 3.19 to 9.45 . The concentration of soil total organic C (soil C hereafter) was determined by colorimetry after oxidation with a mixture of potassium dichromate and sulfuric acid (Anderson \& Ingram, 1989) and ranged from 0.3 to 473.6 g CKg-1. Available P was determined from bicarbonate extracts as described in (Olsen \& Sommers, 1982) and ranged from $<0.01$ to $90.69 \mathrm{mg} \mathrm{P} \mathrm{kg}^{-1}$. Total $\mathrm{N}$ was measured with a $\mathrm{CN}$ analyzer (LECO CHN628 Series LECO Corporation, St Joseph, MI, USA) and ranged from $<0.01$ to 1.379\%. Further details are described in Delgado-Baquerizo et al. (2019)

\section{Cyanobacterial abundance, richness and composition}

To obtain the total abundance of cyanobacteria, quantitative PCR (qPCR hereafter) was performed with specific cyanobacterial primers CYA 359F and CYA $781 \mathrm{R}(\mathrm{a})$ and CYA 781 R(b) (Nübel et al., 1997). Each qPCR reaction contained 5 ul of LightCycler ${ }^{\circledR} 480$ SYBR Green I Master, 0.5 ul of forward primer CYA 359, 0.25 ul of CYA 781 R(a) and $0.25 \mathrm{ul}$ of CYA $781 \mathrm{R}(\mathrm{b})$ reverse primers, $1 \mathrm{ul}$ of template and $3 \mathrm{ul}$ of sterilized water. Reaction conditions included an initial denaturalization stage of 95으 for 5 minutes, followed by 40 cycles of amplification: 95ㅇ $\mathrm{C}$ for $1 \mathrm{~min}, 50^{\circ} \mathrm{C}$ for $1 \mathrm{~min}$ and $72^{\circ} \mathrm{C}$ for 1 min; and finally a melting curve of $95^{\circ} \mathrm{C}$ for $5 \mathrm{~s}$ and $65^{\circ} \mathrm{C}$ for $1 \mathrm{~min}$. The qPCR machine used was a Roche light cycler 480 (Roche Diagnostics, Mannheim, Germany), that uses the Crossing point value, where your sample crosses the threshold fluorescence so you can infer its abundance with standard samples. Cyanobacterial abundance is expressed as $16 \mathrm{~S}$ copies/g soil. All qPCR analyses were done at the facilities of Western Sydney University (Australia).

The primers 515F-806R (Caporaso et al., 2010b) were used to amplify the bacterial V4 region of the 16S SSU rRNA using the Illumina Miseq platform at the Next Generation Genome Sequencing Facility at Western Sydney University (Australia). Bioinformatic processing was performed using a combination of QIIME (Caporaso et al., 2010a), USEARCH (Edgar, 2010) and UNOISE2 (Edgar, 2016). Phylotypes (i.e 
bioRxiv preprint doi: https://doi org/10.1101/2021.09.11.459883; this version posted September 11, 2021. The copyright holder for this preprint (which was not certified by peer review) is the author/funder, who has granted bioRxiv a license to display the preprint in perpetuity. It is made available under aCC-BY-NC-ND 4.0 International license.

Operational Taxonomic Units; OTUs) were identified at the $100 \%$ identity level (zOTUs). Taxonomy was assigned with the online tool Silva Incremental Alligner with Silva database (Pruesse et al., 2012) according to last update (SILVA SSU 138.1), data accessed on 10 March of 2021. The $16 \mathrm{~S}$ zOTU abundance table was rarefied and the relative abundance (\%) of cyanobacteria in relation to total bacterial (16S rRNA) reads was calculated for community analyses. For diversity estimations, Shannon Index (Shannon \& Weaver, 1949) was calculated using the estimate_richness function from the phyloseq R package v1.16.2 (Mcmurdie \& Holmes, 2012). Phylotype richness was highly correlated with the Shannon Index (Spearman $\rho=0.91, p<0.05$ ), so we used it as a surrogate of phylotype diversity. Relative abundances (\%) of cyanobacterial classes and families were calculated for statistical analyses; and sqrt-transformed to improve their goodness of fit to the normal distribution.

\section{Statistical analyses}

We tested the relationship between cyanobacterial abundance and soil development (chronosequence stage and soil age) with linear mixed-effects models. Between both, the stage of the chronosequence was selected because models have larger percentage of variance explained $\left(R^{2}\right)$ than those with soil age (the radiometric dating estimation in years); although similar results were obtained with both approximations.

Linear mixed-effects models were used to analyze the total abundance of cyanobacteria, phylotype richness, and the relative abundances of cyanobacterial classes with stage of the chronosequence as a fixed factor. These analyses allowed us to obtain generalizable results as they consider the chronosequence as a random factor, thus controlling dependencies between plots within a chronosequence. Models were done with Imer function from the Ime4 R package (Bates et al., 2015) and tests for significance were calculated with Imertest R package (Kuznetsova et al., 2017). To further explore the relationships between abundance and phylotype richness through time, linear and polynomic (quadratic and cubic) regression models were fitted. These analyses were performed with the $I m$ function from base R keeping only relationships with $\mathrm{P}<0.05$ and selecting the model with the lowest Akaike Information Criterion (AIC) value (Akaike, 1974). 
We analyzed the changes in the composition of soil cyanobacteria between stages separately for each of the 16 chronosequences surveyed using multivariate PERMANOVAs (Anderson, 2001). These analyses were conducted with Unifracweighted distances and the phyloseq R package (Mcmurdie \& Holmes, 2012). Unifracweighted distances are more informative than non-phylogenetic distance measures because they take into consideration the degree of similarity between phylotypesequences and the relative abundance of each phylotype within samples (weight parameter). In those chronosequences with community changes, subsequent PERMANOVA analyses were done to evaluate the effect of vegetation (through total and tree covers). To determine whether the relative abundances of all cyanobacterial classes and families change between stages, we used multiple univariate PERMANOVAs with Euclidean distances. All PERMANOVA analyses were made with the adonis function and 1000 permutations of the vegan package (Oksanen, 2015)

We investigated the associations between cyanobacterial composition and environmental variables through statistical modelling (SEM) and ordination methods (PCoA). Principal Coordinate Analysis (PCoA) with Unifrac distances was computed to compare the composition of microbial communities among sites using the phyloseq package (Mcmurdie \& Holmes, 2012). To show the influence of environmental variables in the composition of the cyanobacterial community, we made a selection of variables covering vegetation, climate and soil and fitted them into the ordination with envfit function and 9999 permutations with vegan package (Oksanen, 2015). We tested 11 variables including spatial dissimilarity (Euclidean distance between plots), soil age (years), vegetation (tree and grass cover and vascular plant richness), climate (MAT and MAP) and soil ( $\mathrm{pH}$, Soil C, Soil CN and Soil NP) properties. To be included in the analysis, these variables should not be strongly correlated among themselves (Pearson $\rho<0.6$ in all cases). To improve normality, we transformed response variables using either square root (abundance of cyanobacteria, relative abundance of the cyanobacterial classes and plant richness) or natural logarithm (soil age, Soil C, Soil CN and Soil NP) transformations. Since we are comparing variables that are in different scales, and to avoid over or underestimations in our model, all variables included were centred (by subtracting the variable means) and scaled (by dividing the variables by their standard deviations) with the scale function of the R Base package (Team, 2013). Because of the large number of variables tested, a Bonferroni correction test was used 
with the function p.adjust from stats package (Team, 2013) that resulted in the exclusion of MAT and Soil age from the analyses.

Structural equation modelling (SEM) was used to evaluate the direct and indirect effects of the different predictors of the abundance of cyanobacteria and of the relative abundance of the cyanobacterial classes. These include the same 11 variables used in the PCOA ordination and spatial dissimilarity (Euclidean distance between plots) was included to control for spatial autocorrelation of plots within the model. To test the overall fit of the model, we used Chi-square fit test and Root Mean Square Error of Approximation (RMSEA). The model has a good fit when Chi-square/df is low, (i.e. $<2$ ) and $P$ is high $(P>0.05)$ and RMSEA is indistinguishable from zero with a high $P>0.05$. All our indices suggested our model had an adequate model fit so we could interpret path coefficients. Each path coefficient is analogous to a regression weight and describes the strength and sign of the relationships between two variables. To deal with non-normally distributed variables, we used 5000 bootstraps to simultaneously test the significance of each path coefficient. Standardized total effects (direct plus indirect) of all predictors on each cyanobacterial abundance were calculated. SEM analyses were conducted with AMOS 24.0.0 (IBM SPSS, Chicago, IL, USA). The rest of statistical analyses were carried out using R version R-3.6.0 (Team, 2013). 


\section{Results}

\section{Changes in the abundance and diversity of soil cyanobacteria during soil development}

Cyanobacterial abundance and phylotype richness ranged from $1.56 \times 10^{7}$ to $1.83 \times 10^{9}$ copies/g soil and from 1 to 50 phylotypes per sample, respectively. We found no consistent and generalizable effects of chronosequence stage on the richness and abundance of cyanobacteria across contrasting ecosystem types. In general, the richness and abundance of cyanobacteria showed very little and variable association with soil development (see Supplementary Table 3, Fig. S1), remaining stable through time across the contrasting ecosystem types studied. However, we found some associations between chronosequence stage and cyanobacterial diversity and abundance in three and four of the 16 chronosequences evaluated, respectively (Fig. 2). For example, we found an increase in the abundance of these organisms in relatively old temperate chronosequences from Mexico (adjusted $R^{2}=0.15$ ) and Australia (Jurien Bay, adjusted $R^{2}=0.20$ ). Nonlinear relationships between cyanobacterial abundance and soil age were found in Coal Creek and Merced chronosequences with the significant fitting of cubic functions (adjusted $R^{2}=0.18$ and 0.53 respectively) (Fig. $2 a$ and Supplementary Table 4). Cyanobacterial richness decreased with time in the semiarid Substrate Age Gradient of Arizona (SAGA) chronosequence (adjusted $\mathrm{R}^{2}=0.41$ ). Nonlinear cubic relationships between richness and chronosequence stage were found in temperate chronosequences from Chile and Australia (Jurien Bay; adjusted $\mathrm{R}^{2}=0.41$ and 0.53 respectively) (Fig. $2 \mathrm{~b}$ and Supplementary Table 5). Jurien Bay was the only chronosequence experiencing changes in both abundance and diversity of cyanobacteria through time.

\section{Changes in the composition of soil cyanobacterial communities are associated with vegetation changes as soil ages}

In general, the relative abundance of the Sericytochromatia class decreased with chronosequence stage, whereas the other cyanobacterial classes showed variable responses depending on the chronosequence considered (Fig S1, Supplementary Table 3). Most chronosequences were consistently dominated by one of the main ecological groups of cyanobacteria (Cyanobacteriia or Vampirovibrionia classes) over time (Fig. 
3). However, changes in the cyanobacterial composition through time were found in Alps, Conguilio, Lake Michigan and Jurien Bay chronosequences (Fig. 3 and Supplementary Table 6). Differences in the composition of the cyanobacterial community between stages were noticeable even at a high taxonomic level -class level- in these chronosequences. This was confirmed with univariate PERMANOVA analyses in all cases except for Conguilio. A particular turnover pattern was observed in Jurien Bay, Alps and Lake Michigan, where early stages were dominated by photosynthetic cyanobacteria (Cyanobacteriia) and late ones by nonphotosynthetic Vampirovibrionia (Fig. 3). At the family-level, shifts through chronosequence stage in the relative abundances of cyanobacterial families were also observed in chronosequences with significant community changes (see Fig. 4). The relative abundance of $\mathrm{N}$-fixers from the Nostocaceae family decreased as soil aged in Jurien Bay and Alps chronosequences. Similar responses were observed in the Nodosilineaceae family in Lake Michigan and Alps chronosequences.

Changes in the composition of cyanobacterial communities with time occurred in parallel to compositional and structural changes in vegetation. The Alps, Conguilio, Lake Michigan and Jurien Bay chronosequences experienced important changes in vegetation structure and key soil elements (from grasslands to forests; Fig. 3, Fig. S2, Supplementary Table 7). Vegetation shifted from herbaceous to forests in Alps and Lake Michigan, and from cryptogamic covers to shrublands and forests in Conguilio (Fig. 3). Tree and total plant cover had a significant effect on the composition of cyanobacterial communities as soil aged (Supplementary Table 7). The concentration of key soil elements also varied with age in the Alps, Conguilio, Lake Michigan and Jurien Bay chronosequences (Fig. S2), with soil C increasing with soil age in all chronosequences except in Conguilio, as did N and P in the Alps. Soil Nitrogen and available P decreased with soil age in Jurien Bay and Michigan.

\section{Climate, soil and vegetation determine the structure of soil cyanobacterial communities across ecosystems}

Our ordination analyses, which explained a substantial portion of the variance in the cyanobacterial composition (53.5\%, see Fig. 5), showed a major impact of vegetation (plant richness, cover of grasses and trees; $\left.\mathrm{r}^{2}=0.37, \mathrm{p}<0.01\right), \mathrm{pH}\left(\mathrm{r}^{2}=0.32, \mathrm{p}<0.01\right)$ and 
MAP $\left(r^{2}=0.22, p<0.01\right)$ on the composition of soil cyanobacterial communities. The effects of soil age and MAT were not significant. Soil samples were distributed in the PCOA by the presence of forest, confirming that vegetation structure largely regulated the differences in soil cyanobacterial composition across biomes (Fig. 3 and 5).

Structural Equation Models explained $46.6 \%, 22.4 \%$ and $22.8 \%$ of the variance in the relative abundances of Vampirovibrionia, Sericytochromatia, Cyanobacteriia, respectively, and $10.6 \%$ of the variance in the total abundance of cyanobacteria (Fig. 6 and Fig.S4). Vegetation, soil and climate had strong but differing effects on the total and relative abundance of cyanobacteria. Plant richness and tree cover had negative direct effects on the total abundance of cyanobacteria, and on the relative abundance of Cyanobacteriia and Sericytochromatia. In contrast, tree cover promoted the relative abundance of Vampirovibrionia. However, the presence of herbaceous cover (\% grasses cover) had a positive direct effect on relative abundance of Cyanobacteriia and Sericytochromatia. Soil properties and climate also played a key role in regulating cyanobacterial communities. Soil $\mathrm{pH}$ had strong and opposing direct effects on the relative abundances of Vampirovibrionia (negative) and Cyanobacteriia (positive). Similar contrasting relationships were found for organic carbon and the relative abundance of Vampirovibrionia (positive) and Cyanobacteriia (negative). The N:P ratio had a direct positive effect on the relative abundance of Cyanobacteriia, and negative effects on those of Sericytochromatia and Vampirovibrionia. Contrasting associations related to climate were also found, as MAP had a positive direct effect on the relative abundance of Cyanobacteriia and negative total effect on the relative abundance of Vampirovibrionia. MAT had a positive direct effect on the relative abundance of Sericytochromatia and a negative total effect on that of Vampirovibrionia. Soil age had a direct negative effect on the relative abundance of Vampirovibrionia and an indirect negative effect on that of Cyanobacteriia via soil $\mathrm{pH}$ and total organic $\mathrm{C}$. 


\section{Discussion}

Our study provides the first attempt to investigate the changes in soil cyanobacterial communities as soil develops from centuries to millennia across contrasting ecosystems worldwide. We found little effect of soil development per se on the development of cyanobacterial communities. Our study suggests that once soil cyanobacteria are established during primary succession under the dominant vegetation, these communities undergo little changes across long periods of time. However, we found cyanobacterial soil communities changes following big vegetational transitions as those from grasslands to forests, so big structural changes in vegetation are key drivers of temporal cyanobacterial community changes.

\section{Soil cyanobacterial communities do not change during soil development in most of the chronosequences studied}

Our first hypothesis, i.e. that soil age would regulate soil cyanobacterial communities, was not fully supported by our data. On the contrary, most chronosequences rather followed our second hypothesis, which suggests that biome type, and in particular vegetation structure, drives the distribution of cyanobacteria worldwide. In most cases, once a cyanobacterial community became established it is generally dominated by members of a particular class (e.g., Cyanobacteriia or Vampirovibrionia) and the community remains stable from centuries to millennia. Previous studies have shown the large influence of climate on soil photosynthetic Cyanobacteriia (Bahl et al., 2011; Garcia-Pichel et al., 2013; Muñoz-Martín et al., 2019). Vegetation and climate are key determinants of the local diversity of Cyanobacteriia, and therefore have a strong influence on their community assembly. On the other hand, dynamics of nonphotosynthetic cyanobacteria through space and time are much less known. A study from sediments up to 100 years old in perialpine lakes showed no changes in the community structure of non-photosynthetic cyanobacteria through time, as opposed to the highly changing dynamics of photosynthetic Cyanobacteriia (Monchamp et al., 2019). These results suggest that these heterotrophic communities could be shaped by very different environmental drivers than the rest of cyanobacteria through soil development. Here, we observed that Vampirovibrionia dominated across stages in humid temperate forests, and also in the tropical forest of Hawaii and in polar Mount 
Heckla (Iceland). The presence of canopy (\%Tree cover) is beneficial to increment the proportion of this non-photosynthetic group in our soils (positive effects of \%Tree cover see Fig $6 \mathrm{~b})$ as they don't depend on solar irradiation and rather depend on organic matter content. These results agree with previous analyses from an independent global survey showing the preference of Vampirovibrionia for humid forests (Cano-Díaz et al., 2020). The presence of Vampirovibrionia in all soil chronosequences, and specially their dominance even in first stages in Mount Heckla (Iceland), Chichinautzin (Mexico), Hawaii or the Bolivian chronosequences (Cojiri and Chiar Kkollu), indicates that these cyanobacteria are also colonizers of young soils. Similar patterns have been reported previously for glacial chronosequences (Bardgett et al., 2007), where heterotrophic bacterial communities used ancient and recalcitrant carbon as an energy source. On the other side of the ecological spectrum, Cyanobacteriia dominated in arid and semiarid temperate grasslands as they have a preference for areas with low coverage of trees, as seen globally (Garcia-Pichel et al., 2003; Bahl et al., 2011; Cano-Díaz et al., 2020). This way, as tree cover grows the photosynthetic capability of Cyanobacteriia is no longer a beneficial trait and therefore this group loses its dominance (negative effects of \%Trees Fig 6b).

During early primary succession (from years to decades) major successional changes in microbial and vegetation structure are expected (Nemergut et al., 2007; Liu et al., 2016). Previous studies with young chronosequences (up to 10-20 years) showed cyanobacteria increased their abundance and diversity with time (Nemergut et al., 2007; Schmidt et al., 2008a; Dini-Andreote et al., 2014; Liu et al., 2016). In contrast, studies with longer time periods (up to 2000 years) showed initial increases in cyanobacterial abundance followed by a steadily decline (Hodkinson et al., 2003; Brankatschk et al., 2011). Similar patterns were observed in the Merced chronosequence. In Alps and SAGA chronosequences, declines of cyanobacterial abundance and richness, respectively, were observed as soil aged. Conversely, observed increases in cyanobacterial abundance with time in an old chronosequence as Mexico Chichinautzin, and nonlinear responses in Australian Jurien Bay and Chilean Conguilio, are to our knowledge successional patterns not reported before for soil cyanobacteria. These increments could be related to the high proportion of nonphotosynthetic cyanobacteria found in these sites (Fig. 3 and Fig.S5) and the fact that these clades have been recently described. Differences in quantification 
techniques could explain to some degree the differences between our results and those from previous studies using microscopic techniques or the cover of visible species to assess cyanobacterial abundance (Kastovská et al., 2005; Dojani et al., 2011). Also, we include relative abundances of difficult-to-culture groups as nonphotosynthetic cyanobacteria (Soo et al., 2015). Genetic-based quantifications from previous studies from decades or years report steadily declines in cyanobacterial abundance through succession (Kastovská et al., 2005; Dini-Andreote et al., 2014), pointing out to the need to use both longer time scales and a comprehensive survey, such as those used here, to find novel cyanobacterial successional dynamics. Likewise, the changes in the relative proportion of non-photosynthetic cyanobacteria through soil development reported here are fully novel as they have not been studied before. Nevertheless, in most of the chronosequences studied the abundance and richness of cyanobacteria remained stable over time. These findings have important implications for ecosystem functioning as cyanobacteria enhance soil $\mathrm{C}$ and $\mathrm{N}$ contents and stability in early ecosystems, paving the way for the development of late-successional communities (Hooper et al., 2000). This could provide interesting legacy effects for these soil communities, including the resistance/resilience to environmental changes, all due to an initial colonization that is maintained along soil development (Nemergut et al., 2007; Van der Putten et al., 2013).

\section{Shifts in vegetation structure can explain observed changes in soil cyanobacterial communities as soils age}

In the chronosequences from Alps, Conguilio, Jurien Bay and Lake Michigan, we observed that changes in vegetation structure from grasslands to forests during ecosystem development were mirrored by changes in the community of cyanobacteria (Fig. 3 and Fig. 4). In these chronosequences, photosynthetic Cyanobacteriia dominated the first chronosequence stages, being replaced by heterotrophic Vampirovibrionia communities as soils developed. These results are probably associated with a change in limiting resources for cyanobacterial communities from carbon in young ecosystems to soil surface availability and light in mature forests (Garcia-Pichel, 2009; Cano-Díaz et al., 2019). This agrees with previous studies showing that, after an initial colonization and growth of photosynthetic cyanobacteria, they decline at later successional stages (Hodkinson et al., 2003; Brankatschk et al., 2011; 
Dini-Andreote et al., 2014). Thus, our results indicate that land use changes from forests to grasslands (e.g., deforestation) would result in important changes in cyanobacterial communities.

The case of Conguilio temperate chronosequence from Chile shows a clear successional effect on vegetation and soil properties, but these were not apparently translated to soil cyanobacterial communities as non-photosynthetic Vampirovibrionia class dominated all chronosequence stages. The ecology of Vampirovibrionia, as the rest of non-photosynthetic cyanobacteria, is still not well known as it has been studied mainly through metagenome-assembled techniques from environmental sequencing, (Di Rienzi et al., 2013; Soo et al., 2014, 2015, 2017). Vampirovibrionia genomes point to a metabolic capacity for aerobic respiration and a possible adaptation to low oxygen conditions as metagenomes only show C-family oxygen reductases related with microaerobic conditions (Soo et al., 2017). Previous research showed community assemblage of non-photosynthetic cyanobacteria remained stable in contrast with Cyanobacteriia which developed seasonal responses to temperature and organic matter content (Monchamp et al., 2019). Despite community changes were detected in Conguilio at the Zotu level (PERMANOVAs in Supplementary Table 6), further community analyses showed no evident changes, except for the Sericytochromatia class. The decrease in the relative abundance of Sericytochromatia through soil development is a general pattern observed throughout all the chronosequences (Supplementary Table 4 and S2). This pattern appears to be mediated by vegetation because of the negative influence of tree cover and NP ratio on relative abundance of Sericytochromatia along chronosequences (Fig. 6 and Fig. S4). Little is known about the ecology of Sericytochromatia, as less than ten metagenome assembled sequences are available to date (Soo et al., 2017), and further studies are needed before strong generalizations about the mechanisms underlying the results observed can be made.

Changes in the diversity of cyanobacterial communities during the first stages of ecological succession have been previously linked with their functional capacities (e.g., $\mathrm{N}$ fixation) (Pointing \& Belnap, 2012). Filamentous cyanobacteria such as Microcoleus vaginatus are usually the first colonizers of bare soils due to their exopolysaccharide sheath, which make filamentous networks that stabilize soils (Danin et al., 1998; Zhang, 2005; Lan et al., 2012). Afterwards, heterocystous cyanobacteria 
such as Nostoc sp. and Scytonema sp. appear; these species have a highly efficient $\mathrm{N}$ fixing capacity through specialized cells (heterocytes) and sometimes contain pigments (e.g. Scytonemin) that protect them from UV radiation, (Danin et al., 1998; Hu et al., 2004; Lan et al., 2015). In Jurien Bay and Alps, we observed a decrease in Nostocaceae (heterocystous) abundance with soil age (Fig. 4). In these specific chronosequences, our results rather agree with the classical model of long-term ecosystem development where primary production is limited to $\mathrm{N}$ on young soils and $\mathrm{P}$ on older ones (Laliberté et al., 2012). Cyanobacteria appearing in these first stages have the capacity to fix $\mathrm{N}$ (with or without heterocytes), which makes these organisms highly competitive and therefore dominant in the first stages where $\mathrm{N}$ is low (Fig. 6). The enrichment in $\mathrm{N}$ provided by these cyanobacteria is likely a factor promoting the following colonization by vegetation (Wardle et al., 2004; Van der Putten et al., 2013). Interestingly, and in contrast with previous reports on changes on the abundance of cyanobacteria at early stages, community turnover were found in old chronosequences (Jurien Bay is 2000 ky, Conguilio is $5000 \mathrm{ky}$ and Alps is 120 ky; only Lake Michigan is relatively young, 4 ky), which shows the benefits of using multiple sites and ages to test and generalize hypotheses about soil microorganisms.

\section{Concluding remarks}

Unlike what has been reported in studies from early ecosystem succession, we did not find strong and significant effects of soil development on the abundance and diversity of cyanobacteria across the global set of chronosequences studied. These cyanobacteria are directly linked with their surrounding vegetation, as we only found profound community changes in those chronosequences wherein vegetation structure has also undergone important changes over time from grasslands to forests. This cyanobacterial compositional shift was mainly related to a turnover from photosynthetic to non-photosynthetic cyanobacteria. These findings significantly advance our knowledge on the ecology and natural history of soil cyanobacteria. This information is relevant to increase our ability to predict future shifts in soil cyanobacteria driven by climate and land use changes. 


\section{Acknowledgements}

This project received funding from the European Union's Horizon 2020 research and innovation program under the Marie Skłodowska-Curie grant agreement 702057 (CLIMIFUN), a Large Research Grant from the British Ecological Society (agreement $\mathrm{n}$ 은 LRA17\1193; MUSGONET), and from the European Research Council (ERC grant agreement $\mathrm{n}$ 0 647038, BIODESERT). M.D-B. is supported by a Ramón y Cajal grant from the Spanish Government (agreement no RYC2018-025483-I). C.C-D. acknowledges support from BIODESERT. FTM acknowledges support from Generalitat Valenciana (CIDEGENT/2018/041). We would like to thank the researchers involved in the CLIMIFUN project for the help with soil sampling. We also would like to thank Alberto Benavent-González for his help optimizing the cyanobacterial qPCRs in HIE laboratory of Western Sydney University. The authors declare no conflict of interest.

\section{Author Contribution}

M.D.-B designed research, C.C.-D., F.T.M., J.W., J.L , B.S., V.O., B.G. M.D-B., performed research, C.C.-D. J.W. and M.D-B. analyzed data, C.C.-D, M.D.-B and F.T.M. wrote the paper with all authors contributing to the drafts 


\section{References}

Akaike H. 1974. A new look at the statistical model identification. IEEE transactions on automatic control 19: 716-723.

Anderson MJ. 2001. A new method for non-parametric multivariate analysis of variance. Austral Ecology 26: 32-46.

Anderson JM, Ingram JSI. 1989. Tropical soil biology and fertility. CAB international Wallingford.

Arróniz-Crespo M, Pérez-Ortega S, Ríos A de los, Green TGA, Ochoa-Hueso R, Casermeiro MÁ, de la Cruz MT, Pintado A, Palacios D, Rozzi R, et al. 2014. BryophyteCyanobacteria associations during primary succession in recently deglaciated areas of Tierra del Fuego ( Chile ). PLOS ONE 9: 15-17.

Bahl J, Lau MCY, Smith GJD, Vijaykrishna D, Cary SC, Lacap DC, Lee CK, Papke RT, Warren-Rhodes KA, Wong FKY, et al. 2011. Ancient origins determine global biogeography of hot and cold desert cyanobacteria. Nature Communications 2: 161166.

Bardgett RD, Bowman WD, Kaufmann R, Schmidt SK. 2005. A temporal approach to linking aboveground and belowground ecology. 20.

Bardgett RD, Richter A, Bol R, Garnett MH, Ba R, Xu X, Lopez-Capel E, Manning DAC, Hobbs PJ, Hartley IR, et al. 2007. Heterotrophic microbial communities use ancient carbon following glacial retreat. Biology Letters 3: 487-490.

Bates D, Mächler M, Bolker BM, Walker SC. 2015. Fitting linear mixed-effects models using Ime4. Journal of statistical software 67.

Belnap J. 2002. Nitrogen fixation in biological soil crusts from southeast Utah, USA. Biology and Fertility of Soils 35: 128-135.

Blois JL, Williams JW, Fitzpatrick MC, Jackson ST, Ferrier S. 2013. Space can substitute for time in predicting climate-change effects on biodiversity.

Brankatschk R, Töwe S, Kleineidam K, Schloter M, Zeyer J. 2011. Abundances and potential activities of nitrogen cycling microbial communities along a chronosequence of a glacier forefield. : 1025-1037.

Büdel B, Dulić T, Darienko T, Rybalka N, Friedl T. 2016. Cyanobacteria and algae of Biological Soil Crusts. In: Weber B, Büdel B, Belnap J, eds. Biological Soil Crusts: An Organizing Principle in Drylands. Cham: Springer International Publishing, 55-80.

Cano-Díaz C, Maestre FT, Eldridge DJ, Singh BK, Bardgett RD, Fierer N, DelgadoBaquerizo M. 2020. Contrasting environmental preferences of photosynthetic and non-photosynthetic soil cyanobacteria across the globe. Global Ecology and Biogeography: 1-14.

Cano-Díaz C, Maestre FT, Eldridge DJ, Singh BK, Richard D, Fierer N, DelgadoBaquerizo M. 2019. Ecological niche differentiation in soil cyanobacterial communities across the globe. bioRxiv.

Caporaso JG, Kuczynski J, Stombaugh J, Bittinger K, Bushman FD, Costello EK, Fierer N, Peña AG, Goodrich JK, Gordon JI, et al. 2010a. QIIME allows analysis of highthroughput community sequencing data. Nature Methods 7: 335. 
Caporaso JG, Lauber CL, Walters WA, Berg-lyons D, Lozupone CA, Turnbaugh PJ, Fierer N, Knight R. 2010b. Global patterns of $16 \mathrm{~S}$ rRNA diversity at a depth of millions of sequences per sample. Proceedings of the National Academy of Sciences 108: 45164522.

Danin A, Dor I, Sandler A, Amit R. 1998. Desert crust morphology and its relations to microbiotic succession at Mt. Sedom, Israel. : 161-174.

Delgado-Baquerizo M, Bardgett RD, Vitousek PM, Maestre FT, Williams MA, Eldridge DJ, Lambers H, Neuhauser S, Gallardo A, García-Velázquez L, et al. 2019. Changes in belowground biodiversity during ecosystem development. Proceedings of the National Academy of Sciences 116: 1-6.

Dini-Andreote F, Silva M de CP e, Triado-Margarit X, Casamayor EO, Elsas JD Van, Falcao J. 2014. Dynamics of bacterial community succession in a salt marsh chronosequence : evidences for temporal niche partitioning. ISME Journal 8: 19892001.

Dojani S, Büdel B, Deutschewitz K, Weber B. 2011. Rapid succession of Biological Soil Crusts after experimental disturbance in the Succulent Karoo, South Africa. Applied Soil Ecology 48: 263-269.

Edgar RC. 2010. Search and clustering orders of magnitude faster than BLAST. Bioinformatics 26: 2460-2461.

Edgar RC. 2016. UNOISE2 : improved error-correction for Illumina 165 and ITS amplicon sequencing.

Garcia-Pichel F. 2009. Cyanobacteria. In: Schmidt TM, ed. Encyclopedia of Microbiology. Academic Press, 107-124.

Garcia-Pichel F, Belnap J, Neuer S, Schanz F. 2003. Estimates of global cyanobacterial biomass and its distribution. Algological Studies 109: 213-227.

Garcia-Pichel F, Loza V, Marusenko Y, Mateo P, Potrafka RM. 2013. Temperature drives the continental-scale distribution of key microbes in topsoil communities. Science 340: 1574-1577.

Garcia-Pichel F, Wojciechowski MF. 2009. The evolution of a capacity to build supracellular ropes enabled filamentous cyanobacteria to colonize highly erodible substrates. PLOS ONE 4: 4-9.

Hayat R, Ali S, Amara U. 2010. Soil beneficial bacteria and their role in plant growth promotion : a review. : 579-598.

Hodkinson ID, Coulson SJ, Webb NR. 2003. Community assembly along proglacial chronosequences in the high Arctic : vegetation and Soil Development in north-west Svalbard. Journal of Ecology 91: 651-663.

Hooper DU, Bignell DE, Brown VK, Lavelle P, Putten W Van der, Ruiter PC de, Rusek J, Silver WL, Tiedje JM. 2000. Interactions between aboveground and belowground biodiversity in terrestrial ecosystems : patterns, mechanisms and feedbacks.

BioScience 50: 1049-1061.

Hu C, Zhang D, Liu Y. 2004. Research progress on algae of the microbial crusts in arid and semiarid regions. Progress in natural science 14: 289-295.

Kastovská K, Elster J, Stibal M, Santrůcková H. 2005. Microbial assemblages in soil microbial sucession after glacial retreat in Svalbard (High Arctic). Microbial Ecology 50: 396-407. 
Kuznetsova A, Brockhoff PB, Christensen RHB. 2017. ImerTest Package : Tests in Linear Mixed Effects Models. Journal of statistical software $\mathbf{8 2}$.

Laliberté E. 2014. Environmental filtering explains variation in plant diversity along resource gradients. Science 345: 1602-1605.

Laliberté E, Kardol P, Didham RK, Teste FP, Turner BL, Wardle DA. 2017. Soil fertility shapes belowground food webs across a regional climate gradient. Ecology Letters 20: 1273-1284.

Laliberté E, Turner BL, Costes T, Pearse SJ, Wyrwoll K, Zemunik G, Lambers H. 2012. Experimental assessment of nutrient limitation along a 2-million-year dune chronosequence in the south-western Australia biodiversity hotspot. Journal of Ecology 100: 631-642.

Lan S, Wu L, Zhang D. 2012. Successional stages of biological soil crusts and their microstructure variability in Shapotou region ( China ). : 77-88.

Lan S, Wu L, Zhang D, Hu C. 2015. Analysis of environmental factors determining development and succession in biological soil crusts. Science of the Total Environment 538: 492-499.

Lindo Z, Nilsson MC, Gundale MJ. 2013. Bryophyte-cyanobacteria associations as regulators of the northern latitude carbon balance in response to global change. Global Change Biology 19: 2022-2035.

Liu J, Kong W, Zhang G, Khan A, Guo G, Zhu C, Wei X, Kang S, Morgan-kiss RM. 2016. Diversity and succession of autotrophic microbial community in high-elevation soils along deglaciation chronosequence. FEMS Microbiology Ecology 92: 1-11.

Maier S, Tamm A, Wu D, Caesar J, Grube M, Weber B. 2018. Photoautotrophic organisms control microbial abundance, diversity, and physiology in different types of biological soil crusts. ISME Journal 12: 1032-1046.

Mazor G, Kidron GJ, Vonshak A, Abeliovich A. 1996. The role of cyanobacterial exopolysaccharides desert microbial crusts. 21: 121-130.

Mcmurdie PJ, Holmes S. 2012. Phyloseq: A bioconductor package for handling and analysis of high-throughput phylogenetic sequence data. Biocomputing: 235-246.

Monchamp M, Spaak P, Pomati F. 2019. Long Term Diversity and Distribution of Nonphotosynthetic Cyanobacteria in Peri-Alpine Lakes. 9: 1-11.

Moreira C, Vasconcelos V, Antunes A. 2013. Phylogeny and biogeography of cyanobacteria and their produced toxins. Marine Drugs 11: 4350-4369.

Muñoz-Martín MÁ, Becerra-Absalón I, Perona E, Fernández-Valbuena L, Garcia-Pichel F, Mateo P. 2019. Cyanobacterial biocrust diversity in Mediterranean ecosystems along a latitudinal and climatic gradient. New Phytologist 221: 123-141.

Nemergut DR, Anderson SP, Cleveland CC, Martin AP, Miller AE, Seimon A, Schmidt SK. 2007. Microbial community succession in an unvegetated recently deglaciated soil. Microbial Ecology 53: 110-122.

Nübel U, Muyzer G, Garcia-pichel F, Muyzer G. 1997. PCR primers to amplify 165 rRNA genes from cyanobacteria PCR Primers To Amplify 16 S rRNA Genes from Cyanobacteria. Microbiology 63: 3327-3332.

Oksanen J. 2015. Vegan: an introduction to ordination. URL http://cran. r-project. org/web/packages/vegan/vignettes/introvegan. pdf 8: 19. 
Olsen SR, Sommers LE. 1982. Methods of soil analysis: Part 2. Chemical and microbiological properties (AL Page, RH Miller, and DR Keeney, Eds.). Madison, WI: American Society of Agronomy and Soil Science Society of America.

Pointing SB, Belnap J. 2012. Microbial colonization and controls in dryland systems. Nature Reviews Microbiology 10: 551-562.

Pruesse E, Peplies J, Glöckner FO. 2012. SINA: Accurate high-throughput multiple sequence alignment of ribosomal RNA genes. Bioinformatics 28: 1823-1829.

Van der Putten WH, Bardgett RD, Bever JD, Bezemer TM, Casper BB, Fukami T, Kardol P, Klironomos JN, Kulmatiski A, Schweitzer JA, et al. 2013. Plant-soil feedbacks: the past, the present and future challenges. Journal of Ecology 101: 265-276.

Di Rienzi SC, Sharon I, Wrighton KC, Koren O, Hug LA, Thomas BC, Goodrich JK, Bell JT, Spector TD, Banfield JF, et al. 2013. The human gut and subsurface harbor nonphotosynthetic Cyanobacteria. Elife 2:e01102: 1-25.

Rodriguez-Caballero E, Belnap J, Büdel B, Crutzen PJ, Andreae MO, Pöschl U, Weber B. 2018. Dryland photoautotrophic soil surface communities endangered by global change. Nature Geoscience 11.

Schmidt SK, Reed SC, Nemergut DR, Grandy AS, Cleveland CC, Weintraub MN, Hill AW, Costello EK, Meyer AF, Neff JC, et al. 2008a. The earliest stages of ecosystem succession in high-elevation ( 5000 metres above sea level), recently deglaciated soils. : 2793-2802.

Schmidt SK, Reed SC, Nemergut DR, Grandy AS, Cleveland CC, Weintraub MN, Hill AW, Costello EK, Meyer AF, Neff JC, et al. 2008b. The earliest stages of ecosystem succession in high-elevation ( 5000 metres above sea level ), recently deglaciated soils. : 2793-2802.

Shannon CE, Weaver W. 1949. The Mathematical Theory of Communication (CE Shannon and W Weaver, Eds.). Urbana: The University of Illinois Press.

Shih PM, Hemp J, Ward LM, Matzke NJ, Fischer WW. 2017. Crown group Oxyphotobacteria postdate the rise of oxygen. Geobiology 15: 19-29.

Singh JS, Kumar A, Rai AN, Singh DP. 2016. Cyanobacteria : A precious bio-resource in agriculture, ecosystem, and environmental sustainability. Frontiers in Microbiology 7: $1-19$.

Soo RM, Hemp J, Parks DH, Fischer WW, Hugenholtz P. 2017. On the origins of oxygenic photosynthesis and aerobic respiration in Cyanobacteria. Science 355: 14361440.

Soo RM, Skennerton CT, Sekiguchi Y, Imelfort M, Paech SJ, Dennis PG, Steen JA, Parks DH, Tyson GW, Hugenholtz P. 2014. An expanded genomic representation of the phylum Cyanobacteria. Genome Biology and Evolution 6: 1031-1045.

Soo RM, Woodcroft BJ, Parks DH, Tyson GW, Hugenholtz P. 2015. Back from the dead; the curious tale of the predatory cyanobacterium Vampirovibrio chlorellavorus. PeerJ 3: e968.

Team RC. 2013. R: A language and environment for statistical computing.

Tongway D, Hindley N. 2004. Landscape function analysis : a system for monitoring rangeland function Landscape. African Journal of Range \& Forage Science 21: 109-113.

Vitousek PM. 2004. Nutrient cycling and limitation: Hawai'i as a model system. 
Princeton, NJ: Princeton University Press.

Walker LR, Wardle DA, Bardgett RD, Clarkson BD. 2010. The use of chronosequences in studies of ecological succession and soil development. Journal of Ecology 98: 725736.

Wardle DA, Walker LR, Bardgett RD. 2004. Ecosystem properties and forest decline in contrasting long-term chronosequences. Science 305: 509-513.

Whitton BA, Potts M. 2012. Introduction to the cyanobacteria. In: Whitton BA, ed. Ecology of Cyanobacteria II. Springer, 1-13.

Zhang Y. 2005. The microstructure and formation of biological soil crusts in their early developmental stage. Chinese Science Bulletin 50: 117-121.

Zomer RJ, Trabucco A, Bossio DA. 2008. Climate change mitigation: A spatial analysis of global land suitability for clean development mechanism afforestation and reforestation. Agriculture, Ecosystems \& Environment 126: 67-80. 


\section{Figure legends}

Figure 1. Locations of the chronosequences used in this study.

Fig.2 Cyanobacterial abundance (a) and richness (b) through soil development (chronosequence stage) for the 16 chronosequences studied. Lines show significant $(p<0.05)$ model fits between chronosequence stage and cyanobacterial abundance (the fitted model is that with the lowest AIC value among linear, quadratic and cubic models). Details of all fitted models can be found in Supplementary Tables 3 and 4.

Fig.3. Relative abundance of cyanobacterial classes (\%) and vegetation types across stages for all chronosequences. Bottom table: Summary of PERMANOVA results for relative abundances of cyanobacterial classes in chronosequences with large changes in cyanobacterial composition.

Fig. 4: Relative abundance of cyanobacterial families (\%) across stages for all chronosequences. Bottom table: Summary of PERMANOVA results for relative abundances of cyanobacterial families in chronosequences with large changes in cyanobacterial composition. U=Unknown.

Fig.5. Principal Coordinate Analysis (PCoA) of Unifrac-weighted distances of all chronosequence samples representing forested (green) vs. non forested (yellow) sites. Vectors show important environmental variables, correlated with the PC1 and PC2 axes with corrected Bonferroni $p$-values $<0.05$. MAT=Mean Annual Temperature, Soil $\mathrm{C}=$ total organic carbon, Soil $\mathrm{CN}=\mathrm{C}: \mathrm{N}$ ratio, Soil $\mathrm{NP}=\mathrm{N}: \mathrm{P}$ ratio, Trees $=\%$ tree cover, Grasses= \% grass cover.

Fig.6: Summary of Structural equation modelling (SEM) results showing the model with direct effects (a) and a table with direct, indirect and total effects (DE, IE, TE) in (b). Variables included are soil age (years), space (Euclidean distances between plots), climate (MAT, and MAP), vegetation (cover of trees and grasses and plant species richness) and soil properties (Soil CN, Soil NP, Soil C and pH) and dependent variables are the abundance of cyanobacteria (measured via qPCR) and the relative abundances of Vampirovibrionia, Sericytochromatia and Cyanobacteriia (Obtained from Miseq, see methods). Numbers in arrows indicate standardized path coefficients. Only significant paths are shown. Hexagonal boxes in the model refer to multiple variables. Model $X^{2}=0.375, P=0.829 d f=2 . R M S E A=0$; 
bioRxiv preprint doi: https://doi.org/10.1101/2021.09.11.459883; this version posted September 11, 2021. The copyright holder for this preprint (which was not certified by peer review) is the author/funder, who has granted bioRxiv a license to display the preprint in perpetuity. It is made available under aCC-BY-NC-ND 4.0 International license.

$\mathrm{P}=0.925$ The complete SEM model is shown in Fig. S5. MAT=Mean Annual Temperature, Soil $\mathrm{C}=$ total organic carbon, Soil CN= C:N ratio, Soil NP=N:P ratio, Trees $=\%$ tree cover, Grasses $=\%$ grass cover. 


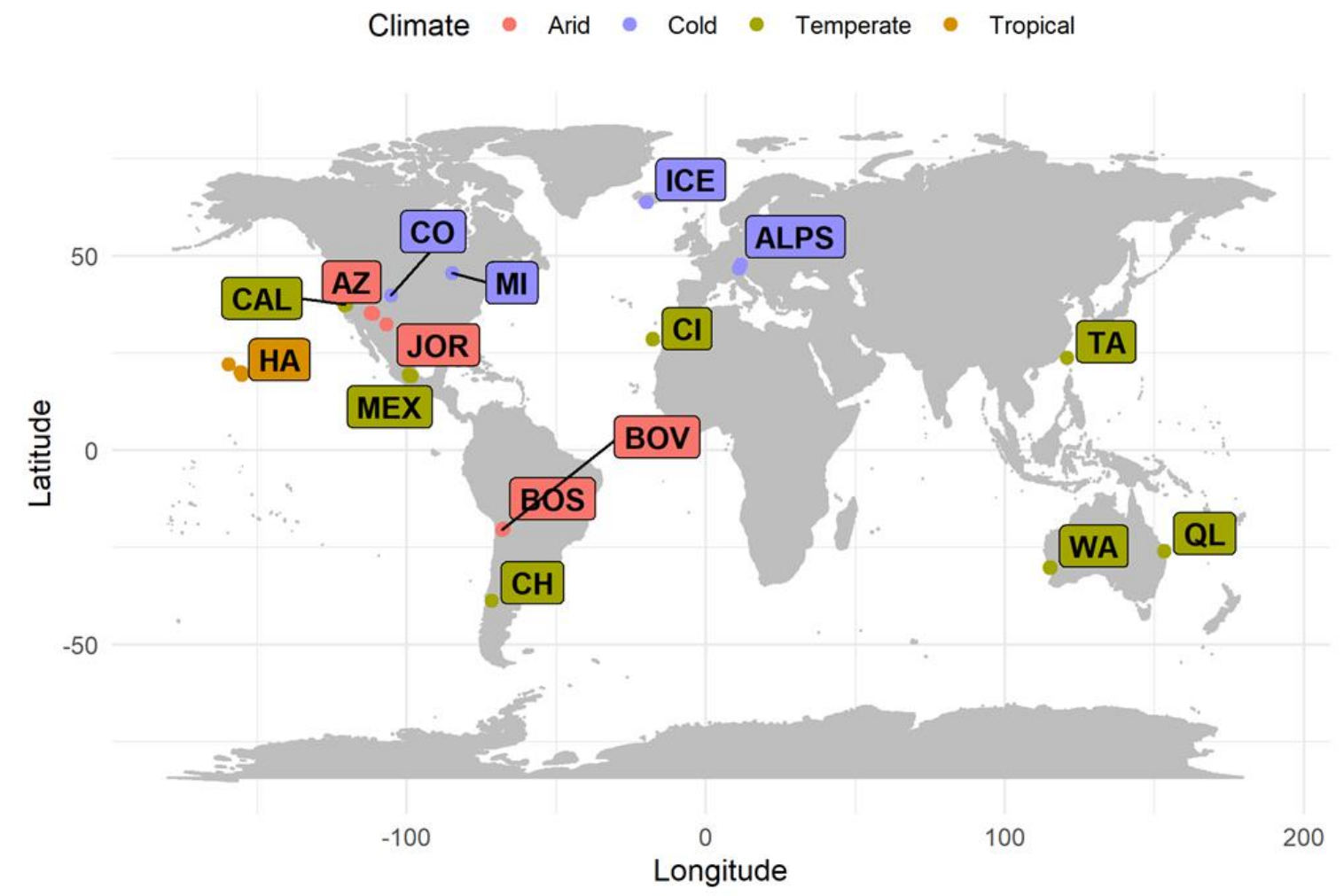

\begin{tabular}{|cccccc|}
\hline Label & Name & Country & Age & Origin & Vegetation \\
\hline ALPS & Alps & Austria & $0.01-120 \mathrm{ky}$ & Glacier & Forest \\
AZ & SAGA & USA & $0.9-3000 \mathrm{ky}$ & Volcanic & Open forest \\
BOS & Cojiri & Bolivia & $0.025-20 \mathrm{ky}$ & Sedimentary & Open shrubland \\
BOV & Chiar Kkollu & Bolivia & $0.025-20 \mathrm{ky}$ & Volcanic & Open shrubland \\
CAL & Merced & USA & $0.1-3000 \mathrm{ky}$ & Sedimentary & Grassland \\
CH & Conguillio & Chile & $0.06-5000 \mathrm{ky}$ & Volcanic & Forest \\
CI & La Palma & Spain & $0.5-1700 \mathrm{ky}$ & Volcanic & Open forest \\
CO & Coal creek & USA & $5-2000 \mathrm{ky}$ & Sedimentary & Grassland \\
HA & Hawaii & USA & $0.3-4100 \mathrm{ky}$ & Volcanic & Forest \\
ICE & Mt Hekla & Iceland & $0.1-0.9 \mathrm{ky}$ & Glacier & Shrubland \\
JOR & Jornada Desert & USA & $1.1-25 \mathrm{ky}$ & Sedimentary & Forblands \\
MEX & Chichinautzin & Mexico & $1-100 \mathrm{ky}$ & Volcanic & Forest \\
MI & Lake Michigan & USA & $0.7-4 \mathrm{ky}$ & Sand dunes & Forest \\
QL & Cooloola & Australia & $3.6-716 \mathrm{ky}$ & Sand dunes & Open forest \\
TA & Taiwan & Taiwan & $28-399 \mathrm{ky}$ & Sedimentary & Cropland \\
WA & Jurien Bay & Australia & $0.1-2000 \mathrm{ky}$ & Sand dunes & Open shrubland \\
\hline
\end{tabular}

Fig 1 
bioRxiv preprint doi: https://doi org/10.1101/2021.0911 459883; this version posted September $11,2021$. The copyright holder for this preprint (which was not certified by peer review) is the author/funder, who has granted bioRxiv a license to display the preprint in perpetuity. It is made available under aCC-BY-NC-ND 4.0 International license.

a
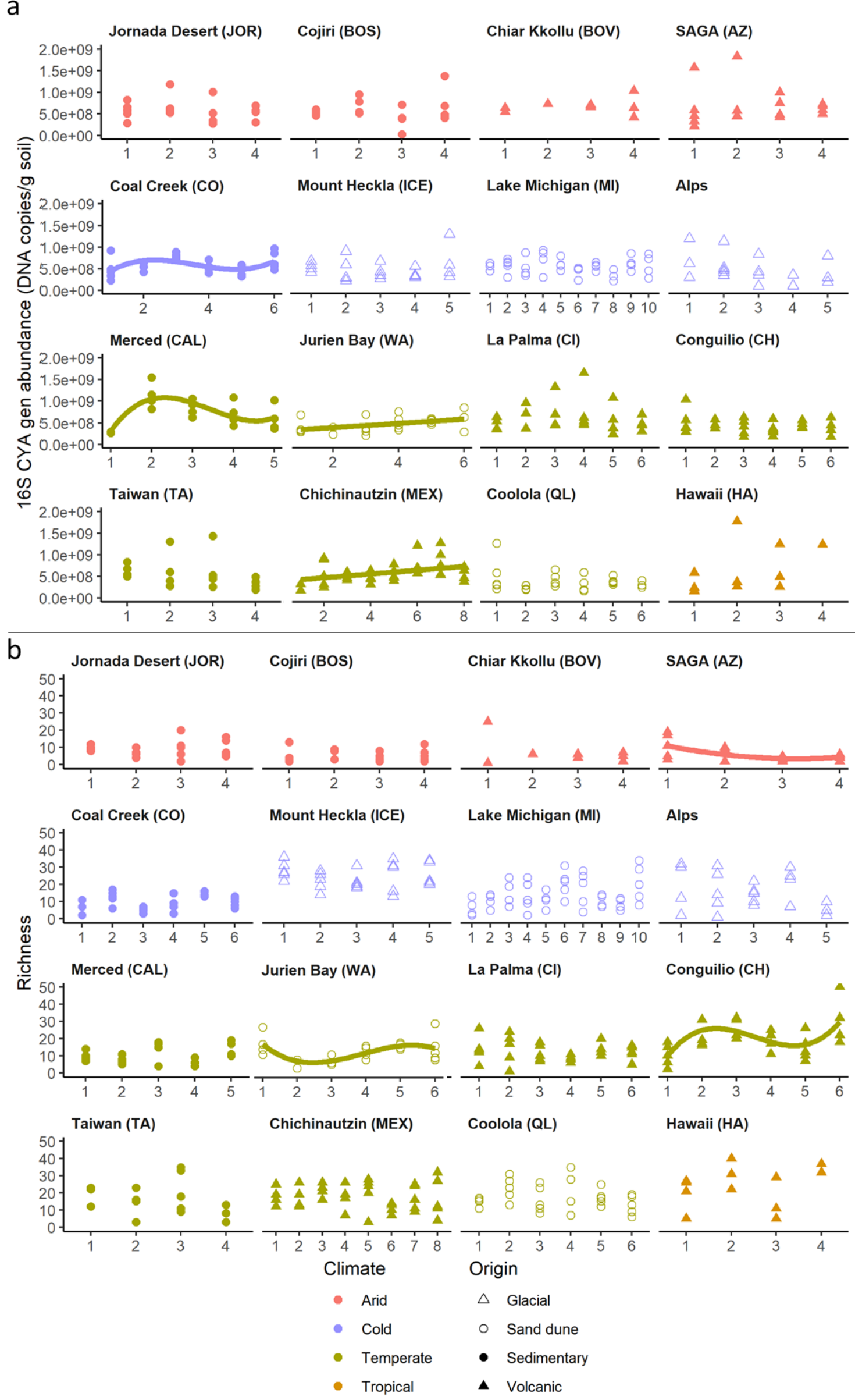

Fig. 2 
bioRxiv preprint doi: https://doi. org/10.1101/2021.09.11.459883. this version posted September 11 2021. The copyright holder for this preprint (which was not certified by peer review) is the author/funder, who has granted bioRxiv a license to display the preprint in perpetuity. It is made available under aCC-BY-NC-ND 4.0 International license.

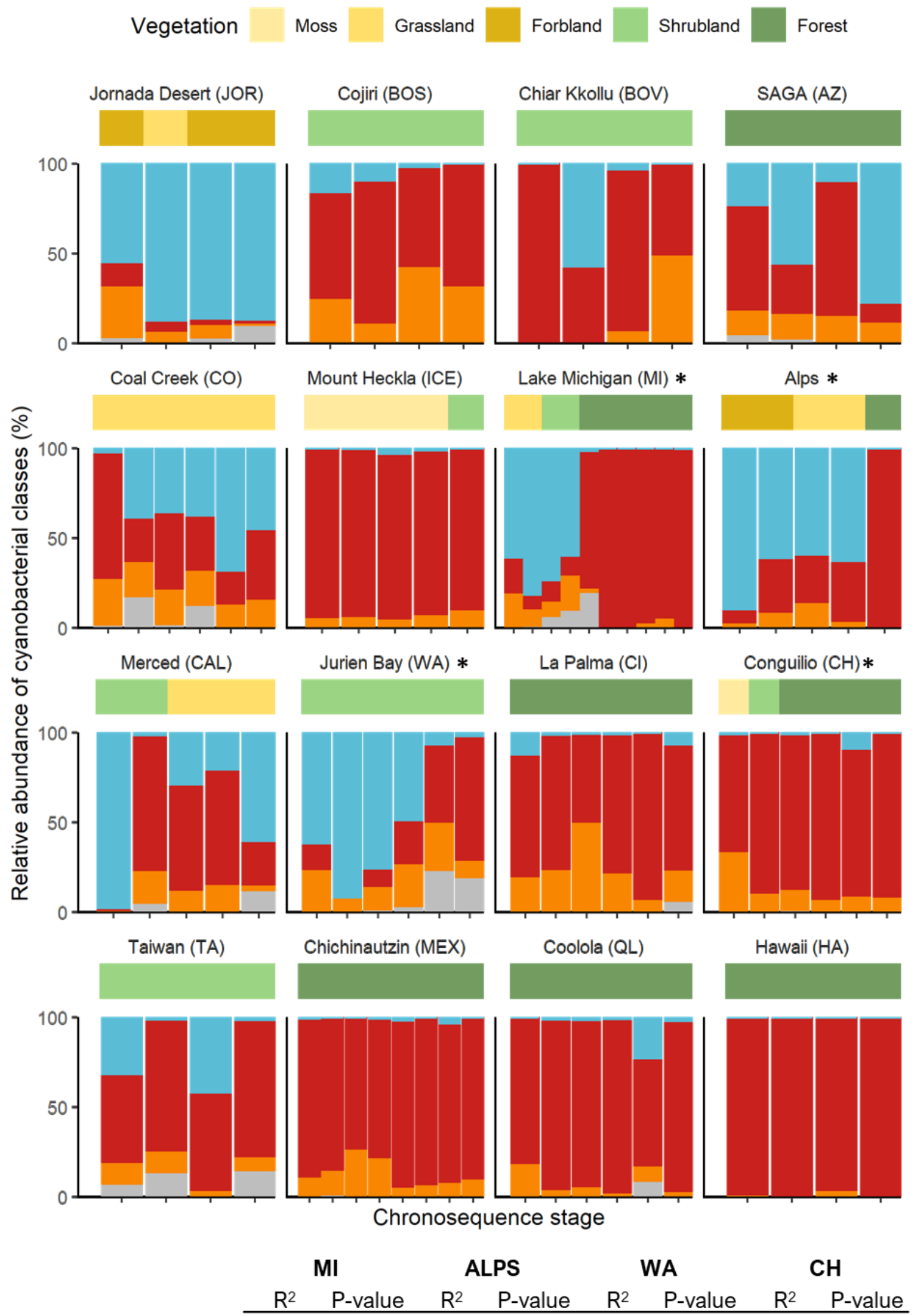

\section{Class}

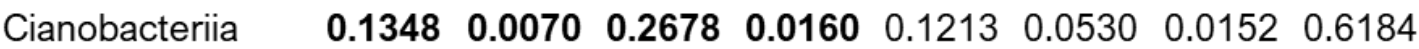

$\begin{array}{lllllllll}\text { Vampirovibrionia } & 0.1584 & 0.0070 & 0.0966 & 0.1489 & 0.1963 & 0.0110 & 0.0023 & 0.8272\end{array}$

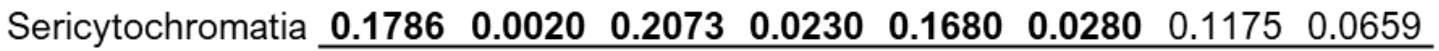

Fig. 3 
bioRxiv preprint doi: https://doi org/10.1101/2021.09.11.459883; this version posted September 11, 2021. The copyright holder for this preprint (which was not certified by peer review) is the author/funder, who has granted bioRxiv a license to display the preprint in perpetuity. It is made available under aCC-BY-NC-ND 4.0 International license.

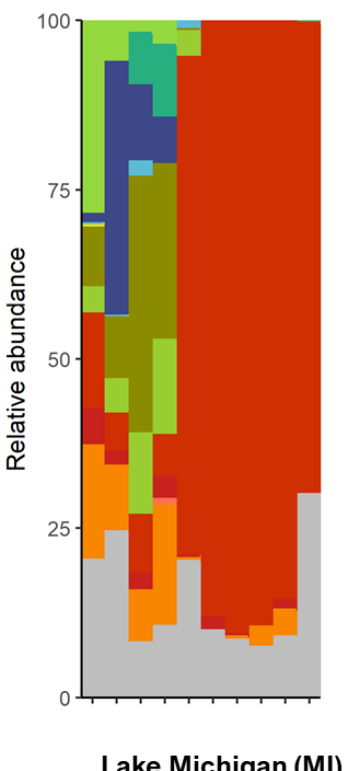

Family

Chroococcidiopsaceae

Coleofasciculaceae

Cyanobacteriaceae

Xenococcaceae

Phormidiaceae

Leptolyngbyaceae

Nodosiliniaceae

Nostocaceae

Obscuribacteraceae

Vampirovibrionaceae

U. Cyanobacteriia

U.Vampirovibrionia

U. Sericytochromatia

Unknown

Fig. 4

P-value

0.0010

$\begin{array}{ll}\mathbf{0 . 2 4 2 5} & \mathbf{0 . 0 0 1 0} \\ 0.0198 & 0.4016\end{array}$

$\mathbf{0 . 0 7 2 1} \quad \mathbf{0 . 0 4 0 0}$

0.4436

$\mathbf{0 . 0 4 5 0}$

$\mathbf{0 . 0 8 4 5}$

$0.0544 \quad 0.0969$

$\mathbf{0 . 0 0 5 0}$

0.1713

0.1109

0.0571
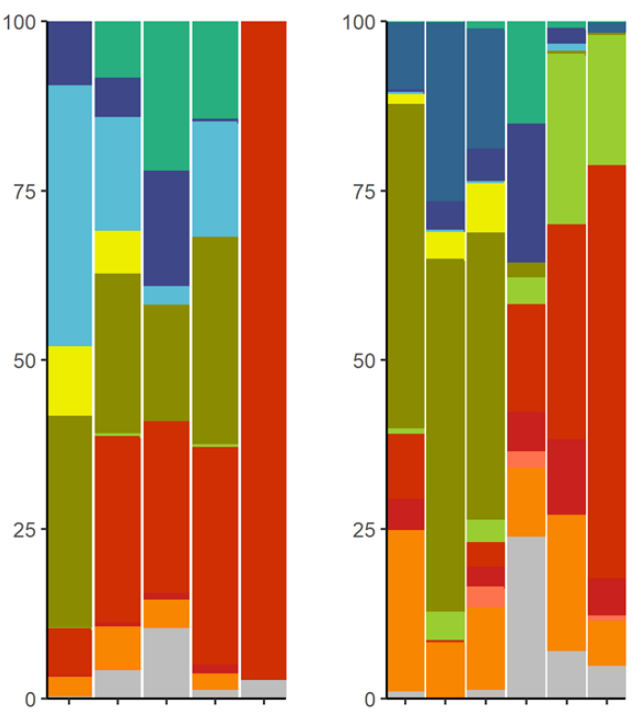

Jurien Bay (WA)

Alps

$\mathrm{R}^{2}$

P-value

$\mathrm{R}^{2}$

P-value

0.0014

0.8911

$0.0245 \quad 0.5065$

0.1767

0.0200

0.9491

0.2470

0.0080

0.1911

0.0270

0.0002

0.9491
0.6194

0.2688

0.0080

0.2316

$\mathbf{0 . 0 2 7 0}$

0.1357

0.0559

0.0004

0.1469

0.1791

0.0040

0.0210

0.0247

0.5075

0.9301

0.0000

0.9800

0.0004

0.9201

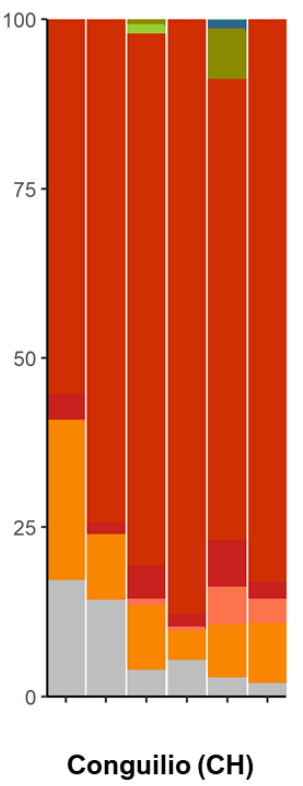

$\mathrm{R}^{2}$

P-value 
bioRxiv preprint doi: https://doi.org/10.1101/2021.09.11.459883; this version posted September 11,2021 . The copyright holder for this preprint (which was not certified by peer review) is the author/funder, who has granted bioRxiv a license to display the preprint in perpetuity. It is made available under aCC-BY-NC-ND 4.0 International license.

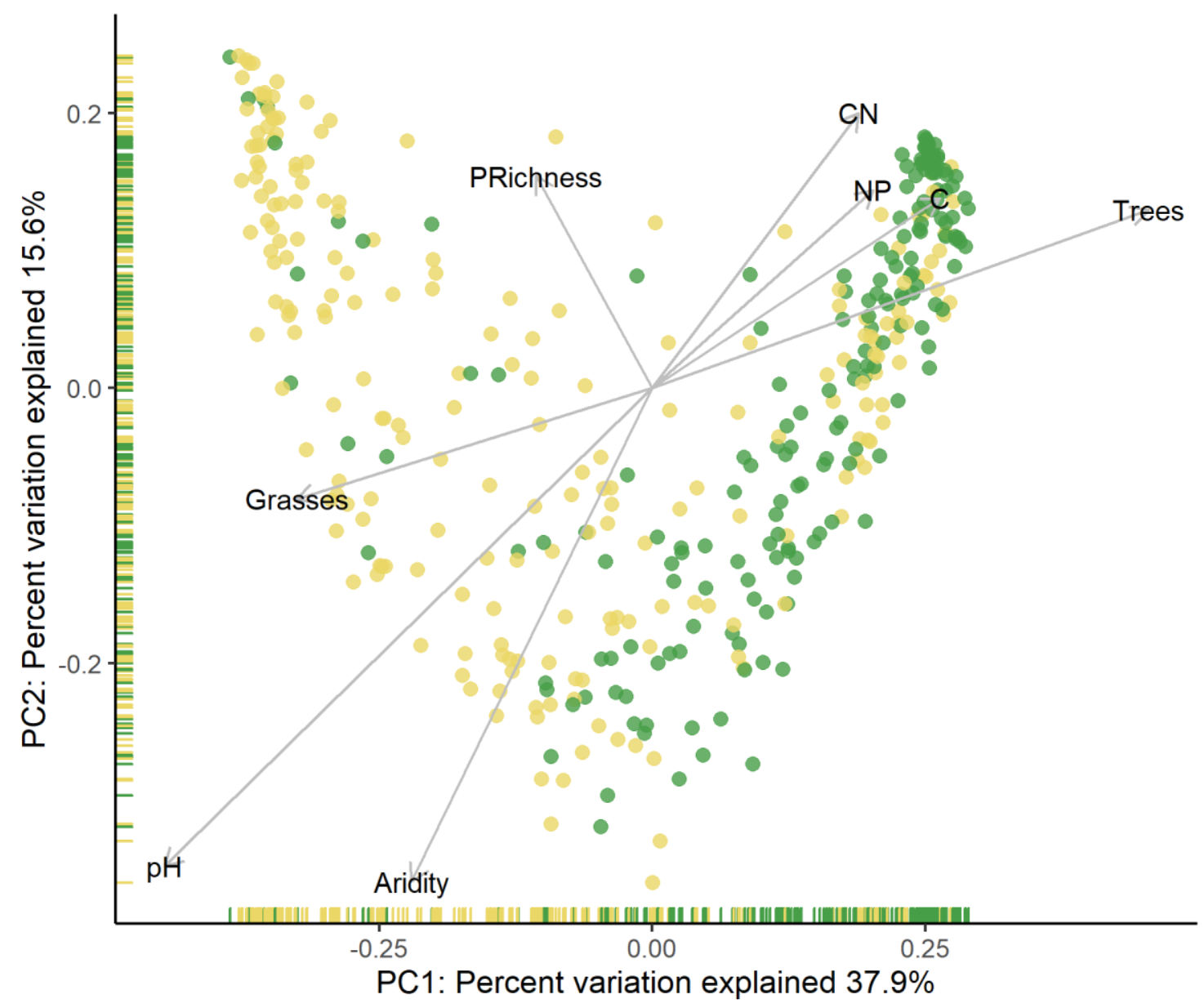

Fig.5 
bioRxiv preprint doi: https://doi org/10.1101/2021.09.11.459883; this version posted September 11, 2021. The copyright holder for this preprint (which was not certified by peer review) is the author/funder, who has granted bioRxiv a license to display the preprint in perpetuity. It is made available under aCC-BY-NC-ND 4.0 International license.

a

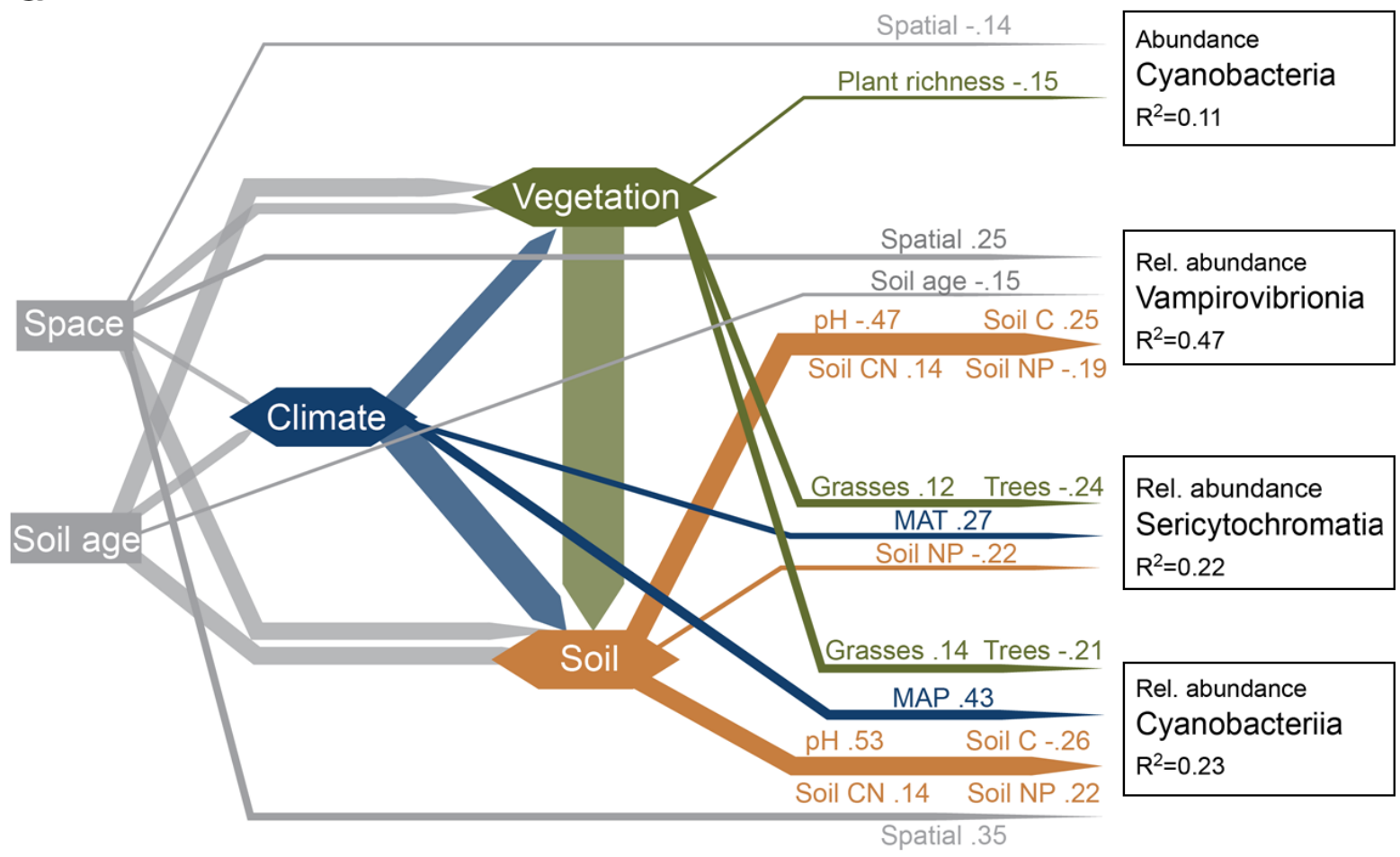

b

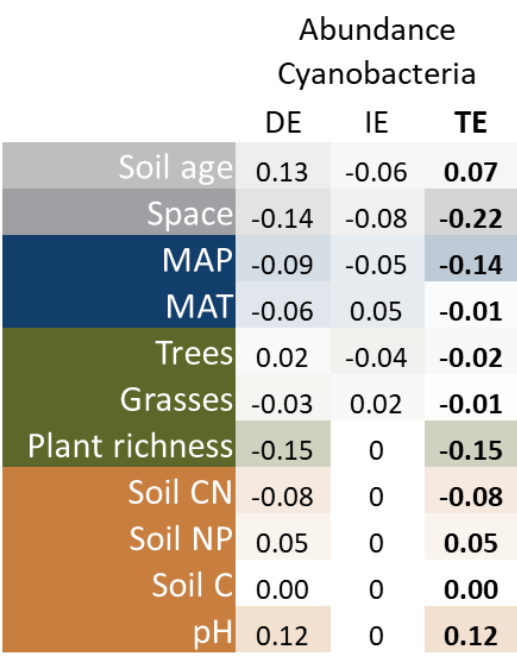

Rel. Abundance

Vampirovibrionia

DE IE TE

$\begin{array}{lll}-0.15 & 0.11 & -0.03\end{array}$

$\begin{array}{lll}0.25 & -0.08 & 0.17\end{array}$

$\begin{array}{lll}0.08 & 0.44 & 0.51\end{array}$

$\begin{array}{lll}-0.02 & -0.06 & -0.09\end{array}$

$\begin{array}{lll}0.11 & 0.13 & 0.24\end{array}$

$\begin{array}{lll}-0.04 & -0.02 & -0.06\end{array}$

$\begin{array}{lll}-0.08 & 0.03 & -0.05\end{array}$

\begin{tabular}{l|l|l|}
0.14 & 0 & $\mathbf{0 . 1 4}$
\end{tabular}

$-0.19 \quad 0 \quad-0.19$

$0.25 \quad 0 \quad 0.25$

$\begin{array}{llll}-0.47 & 0 & -0.47\end{array}$
Rel. Abundance

Sericytochromatia

DE IE TE

$\begin{array}{lll}-0.05 & -0.01 & -0.07\end{array}$

$\begin{array}{lll}0.05 & -0.01 & \mathbf{0 . 0 4}\end{array}$

$\begin{array}{llll}0.16 & -0.31 & -0.15\end{array}$

$\begin{array}{llll}0.27 & -0.04 & \mathbf{0 . 2 3}\end{array}$

$\begin{array}{llll}-0.24 & -0.13 & -0.37\end{array}$

$\begin{array}{llll}0.12 & -0.10 & \mathbf{0 . 0 2}\end{array}$

$\begin{array}{llll}0.08 & -0.05 & \mathbf{0 . 0 3}\end{array}$

$\begin{array}{lll}0.05 & 0 & \mathbf{0 . 0 5}\end{array}$

$\begin{array}{lll}-0.22 & 0 & -0.22\end{array}$

$\begin{array}{lll}-0.01 & 0 & -0.01\end{array}$

\begin{tabular}{ll|l|l|l|l|l|l|}
0.18 & 0 & 0.18
\end{tabular}
Rel. Abundance

Cianobacteriia

DE IE TE

$\begin{array}{llll}-0.07 & -0.16 & -0.23\end{array}$

$\begin{array}{llll}-0.35 & 0.25 & -0.11\end{array}$

$\begin{array}{llll}0.43 & -0.54 & -0.11\end{array}$

$\begin{array}{llll}-0.03 & 0.04 & \mathbf{0 . 0 1}\end{array}$

$\begin{array}{lll}-0.21 & -0.02 & -0.23\end{array}$

$\begin{array}{lll}0.14 & -0.06 & \mathbf{0 . 0 9}\end{array}$

\begin{tabular}{l|l|l|}
0.06 & 0.01 & $\mathbf{0 . 0 7}$
\end{tabular}

$\begin{array}{lll}0.14 & 0 & 0.14\end{array}$

$\begin{array}{lll}0.22 & 0 & 0.22\end{array}$

$\begin{array}{llll}-0.26 & 0 & -0.26\end{array}$

$\begin{array}{llll}0.53 & 0 & 0.53\end{array}$

Fig. 6 